\title{
PHENOTYPIC FEATURES OF ENDOMETRIAL TUMORS IN PATIENTS WITH FAMILY HISTORY OF CANCER
}

\author{
L.G. Buchynska, N.P. Iurchenko*, N.M. Glushchenko, I.P. Nesina \\ R.E. Kavetsky Institute of Experimental Pathology, Oncology and Radiobiology, NAS of Ukraine, \\ Kyiv 03022, Ukraine
}

\begin{abstract}
Aim: To determine the peculiarities of expression of a number of proteins-regulators of the cell cycle in endometrial cancer (EC) cells in patients with a family history of oncological pathologies. Patients and Methods: 95 EC patients (stage I-II) were included into the study. Clinical-genealogical analysis was performed. 54 patients (group I) had healthy relatives, and in families of 41 patients (group II) an aggregation of malignant tumors of different genesis (mainly tumors of the gastrointestinal tract and the female reproductive system) was recorded. p53, p21 ${ }^{\mathrm{WAF} 1 / \mathrm{CIP1}}, \mathrm{p16}^{\mathrm{INK4a}}$, and Ki-67 were assessed immunohistochemically in the surgical samples. Results: In the majority of patients, both from group I and II, moderately differentiated tumors were observed (in 38.9 and $46.3 \%$ of cases, respectively), mainly with deep myometrium invasion (64.8 and 58.5\% of cases, respectively). In EC patients from group II, a significantly higher number of p16 ${ }^{\mathrm{INK} 4 \mathrm{a}}$-positive cells $(17.7 \pm 1.7 \% ; p=0.001)$ and lower number of p53-positive $(30.9 \pm 3.2 \%$; $p=0.05)$ and Ki-67-positive $(26.9 \pm 2.7 \% ; p=0.048)$ cells was observed compared to those in tumors of patients from group I $(12.0 \pm 1.6 ; 37.7 \pm 2.8$ and $36.7 \pm 3.4 \%$, respectively). Conclusion: Phenotypic features of the EC in the patients with family history of cancer differ from those in tumors of patients without such aggregation. The biological heterogeneity of EC seems to relate to the oncogenealogical history of patients. Also this biological heterogeneity is linked to the molecular features of EC cells, which affects cancer aggressiveness and the course of the disease.
\end{abstract}

Key Words: endometrial cancer, family history of cancer, biomarkers, p53, p21 ${ }^{\mathrm{WAF1} / \mathrm{CIP} 1}, \mathrm{p}^{\mathrm{INK} 4 \mathrm{a}}$, Ki-67.

Endometrial cancer $(\mathrm{EC})$ is one of the most common malignant neoplasms of the reproductive system in women, both in Ukraine and in other European countries. In the structure of oncological pathology of the female population, according to the National Cancer Register, in 2015 EC occupied the third place [1]. This oncopathology occurs predominantly in women over 50 years old, but according to the results of oncoepidemiological studies in recent years the number of EC patients in young and middle age has increased, in particular, $4.0 \%$ of cases are diagnosed before the age of 40 , which definitely affects the demographic situation. It should be noted that at the time of diagnosis of EC metastases are detected in $17.0 \%$ of patients [2].

It has been established that the pathogenesis of EC, as well as the majority of malignant neoplasms, is associated with the influence of hereditary factors and exo- or endogenous factors. On the basis of clinical and genealogical analysis of families of EC patients from the Kyiv region, the contribution of the genetic component to the development of EC is $53.2 \%$, indicating the significant importance of hereditary factors in the occurrence of this pathology [3]. The incidence of hereditary malignant tumors of the reproductive system in women, including EC, varies from 5.0 to $10.0 \%$ [4-6]. To date, there are a number of hereditary cancer syndromes, with a systemic predisposition to the emergence of EC. Most often, EC develops in patients with Lynch syndrome (hereditary non-polyposis colorectal cancer), the development

Submitted: October 12, 2017.

${ }^{\star}$ Correspondence: E-mail: laboncogen@gmail.com Abbreviations used: CDK - cyclin-dependent kinase; EC - endometrial cancer; $\mathrm{LI}$ - labeling index; $\mathrm{PI}$ - proliferation index. of which is associated with inactivation of genes responsible for the repair of unpaired DNA bases $(\mathrm{MSH} 2$, MLH1, MSH3, MSH6, PMS1, PMS2). In addition, this oncopathology is observed in Lee-Fraumeni syndrome (mutation in the TP53 gene), Cowden syndrome (a mutation in the PTEN gene), BRCA-associated breast and ovarian cancer syndrome (BRCA gene inactivation), and others $[4,7,8]$.

Numerous studies have shown that in most cases EC is hormone-dependent malignancy associated with the chronic effects of estrogen on the background of an impaired estrogen-progesterone balance and is heterogeneous in terms of molecular genetic characteristics that are.

Hyperestrogenemia is one of the factors that modulates the expression of genes, which leads to violations in the regulation of cellular signals and contributes to the pathological proliferation of EC cells $[9,10]$. The latter is associated with the progression of neoplasm: determines the rate of growth, malignancy, invasive and metastatic potential of neoplasm [11]. Impairment of the proliferation in tumor cells is associated with a functional imbalance of regulatory genes, in particular, the oncosuppressor gene TP53, cyclindependent kinase (CDK) inhibitors $p 21^{\text {WAF } 1 / C I P 1}$ and $C D K N 2 A / p 16^{1 N K 4 a}$ [12]. The products of these genes are the key components of the p53/p2 $21^{\text {WAF } 1 / \mathrm{CIP} 1}$ and $\mathrm{pRb} / \mathrm{p} 16^{\mathrm{INK} 4 \mathrm{a}}$ signaling pathways, inactivation of which results in uncontrolled proliferation of tumor cells and determines the biology of malignant tumors [13-18]. Our previous studies have shown that EC is characterized by high proliferative activity, which is due to changes in expression of the cell cycle regulators such as p53, p21 $1^{\mathrm{WAF} 1 / \mathrm{CIP} 1}$ and $\mathrm{p} 16^{\mathrm{INK} 4 \mathrm{a}}$, and is associated with the tumor differentiation grade [19]. 
According to current views on the pathogenesis of tumors of the female reproductive system, genetic factors play an important role in shaping the biological characteristics of malignant tumors that may determine prognosis. According to some authors, sporadic and hereditary forms of breast and ovarian cancer are characterized by certain morphological, clinical and functional differences, in particular, the degree of malignancy, the hormone receptor phenotype, the course of the disease, etc. [4, 7, 8]. Despite the achievements in the field of oncology, to this time in clinical practice insufficient attention is paid to the assessment of the role of hereditary factors that determine the biological features of malignant neoplasms and the clinical polymorphism of the disease. Data on the biological features of endometrial tumors occurring in patients with a family history of cancer are practically absent in the modern literature.

Taking into account the above-mentioned, the aim of the study was to determine the expression of the cell cycle regulatory proteins in $\mathrm{EC}$ of the patients with a family history of cancer.

\section{MATERIALS AND METHODS}

The work was performed on the surgical samples of $95 \mathrm{EC}$ patients in FIGO stages I or II who did not receive special treatment before surgery. The patients were operated in the research department of oncogynecology at the National Cancer Institute of the Ministry of Health of Ukraine. An average age of the patients was $58.3 \pm 1.1$ years (from 36 to 83 years). Genealogical information on the burden of a family history of cancer was obtained in a direct survey of EC patients. All patients were informed and agreed to use their private information and operational material for research.

The study of family history of EC patients was carried out with the help of a specially developed clinical genealogy card, which included information on the diseases of relatives of the I and II relation degree, the patient's living conditions and related diseases. The criteria for the distribution of EC patients to the group with a burdened family history of oncological pathology were: presence in the proband's family of two or more relatives with the I relation degree, or one relative of the I relation degree and two of the II degree with neoplasms of the female reproductive system and the gastrointestinal tract and the earlier age $(\leqslant 50$ years) of the manifestation of the disease [20]. In addition, information was taken into account on the clinical course of the disease, the depth of invasion of the tumor in myometrium, the survival rate of patients after treatment, which was obtained in the study of disease history and outpatient card.

The morphological diagnosis and tumor differentiation grade were determined on preparations stained with hematoxylin and eosin according to WHO criteria (2014) [21].

To determine the cell counts in the phases of the mitotic cycle, a flow cytometry using flow cytometer EPICSXL (Becton Coulter, USA). Cell suspension from surgical EC samples was prepared by mechanical disaggregation of the tissue using a special device called Medimachine (Becton Dickinson, Italy), followed by propidium iodide (Sigma-Aldrich, USA) staining.

Immunohistochemical detection of biomarkers was performed on parallel deparaffined sections using primary monoclonal antibodies against Ki-67 (clone MIB-1; Dako, Denmark), p53 (clone DO-7; Dako, Denmark), p21 ${ }^{\text {WAF } 1 / \text { IPP } 1}$ (clone HZ52; Dako, Denmark), p16 ${ }^{\text {INK4a }}$ (clone JC8; Abcam, UK), and PolyVue HRP/ DAB Detection System (Diagnostic BioSystems, USA).

The results of immunohistochemical reaction were evaluated by a semi-quantitative method by counting the percentage of positively stained cells (labeling index - LI). The proliferative potential was determined by the number of cells expressing the marker of proliferation Ki-67 (proliferation index - PI). Expression of markers was analyzed per 1000 tumor cells. The significance of the $\mathrm{LI}$ and the PI less than the median was considered to be low for the expression of the corresponding marker, and with the values of $\mathrm{LI}$ and $\mathrm{PI}$ above median - high. It was found that median expression of $\mathrm{Ki}-67$ in sporadic EC was $31.4 \%$, in the EC of patients with family history of cancer, the Ki-67 expression was $29.0 \%$.

The data were processed using the Statistica 7.0 software package (StatSoft, Inc., USA). The following statistical methods were used: standard descriptive, nonparametric (Mann - Whitney, $x^{2}$-test), correlation (Spearman correlation coefficient). $p<0.05$ was considered statistically significant. The analysis of survival of EC patients was performed using the Kaplan - Meier method.

\section{RESULTS}

The analysis of clinical-genealogical data on pedigrees of 54 EC patients (Group I) found no aggregation of oncological pathology, while in families of 41 probands (Group II) there was revealed the accumulation of malignant tumors of different genesis (Table 1). Most often these were the tumors of the gastrointestinal tract and the female reproductive system.

Table 1. Aggregation of malignant neoplasms in proband families patients with EC

\begin{tabular}{|c|c|c|c|c|c|c|c|}
\hline \multirow[b]{2}{*}{$\begin{array}{l}\text { Degree } \\
\text { of relation- } \\
\text { ship }\end{array}$} & \multicolumn{7}{|c|}{ Tumor type, n (\%) } \\
\hline & EC & BC & $O C$ & CGIT & LC & $\begin{array}{c}\text { Other } \\
\text { localiza- } \\
\text { tions }\end{array}$ & Total \\
\hline $\begin{array}{l} \\
\text { (mother, fa- } \\
\text { ther, sister, } \\
\text { brother, chil- } \\
\text { dren) }\end{array}$ & $\begin{array}{c}10 \\
(15.4)\end{array}$ & $\begin{array}{c}9 \\
(13.8)\end{array}$ & $\begin{array}{c}3 \\
(4.6)\end{array}$ & $\begin{array}{c}20 \\
(30.8)\end{array}$ & $\begin{array}{c}11 \\
(16.9)\end{array}$ & $\begin{array}{c}12 \\
(18.5)\end{array}$ & 65 \\
\hline $\begin{array}{l}\text { II } \\
\text { (aunt, uncle, } \\
\text { grandmother, } \\
\text { grandfather) }\end{array}$ & $\begin{array}{c}9 \\
(17.3)\end{array}$ & $\begin{array}{c}7 \\
(13.5)\end{array}$ & - & $\begin{array}{c}23 \\
(44.2)\end{array}$ & $\begin{array}{c}7 \\
(13.5)\end{array}$ & $\begin{array}{c}6 \\
(11.5)\end{array}$ & 52 \\
\hline Total & $\begin{array}{c}19 \\
(16.2) \\
\end{array}$ & $\begin{array}{c}16 \\
(13.6) \\
\end{array}$ & $\begin{array}{c}3 \\
(2.6) \\
\end{array}$ & $\begin{array}{c}43 \\
(36.8) \\
\end{array}$ & $\begin{array}{c}18 \\
(15.4) \\
\end{array}$ & $\begin{array}{c}18 \\
(15.4)\end{array}$ & 117 \\
\hline
\end{tabular}

Note: ${ }^{*} \mathrm{BC}$ - breast cancer; CGIT - cancer of the gastrointestinal tract (colorectal, stomach, esophagus, liver, pancreas, gallbladder); OC - ovarian cancer; LC - lung cancer.

It should be noted that in families of 24 (58.5\%) EC patients an aggregation of tumors of the colon, 
stomach, endometrium, and ovary was observed. The association of EC, breast cancer and ovarian cancer was found in 10 (24.4\%) pedigrees, and in 7 (17.1\%) EC patients was revealed in relatives of the I and II relation degree [22, 23].

Comparison of the age of manifestation of oncological disease in two groups of patients showed that in patients with a family history of cancer, EC occurred at a younger age (55.7 $\pm 1.5 \%)$, compared with those in patients without aggregation of cancer pathology in pedigrees (Table 2).

Table 2. Clinical and morphological characteristics of EC patients depending on a family history of cancer

\begin{tabular}{|c|c|c|}
\hline \multirow[b]{2}{*}{$\begin{array}{c}\text { Clinical and morphological } \\
\text { parameters }\end{array}$} & \multicolumn{2}{|c|}{ Number of EC cases, $\mathrm{n}(\%)$} \\
\hline & $\begin{array}{l}\text { Without aggregation } \\
\text { of oncological patholo- } \\
\text { gy in families, } \\
N=54\end{array}$ & $\begin{array}{l}\text { With aggregation } \\
\text { of oncological pa- } \\
\text { thology in families, } \\
\qquad N=41\end{array}$ \\
\hline Average age (range), years & $\begin{array}{c}63.2 \pm 1.4 \\
(50-76)\end{array}$ & $\begin{array}{c}55.7 \pm 1.5 \\
(26-59)\end{array}$ \\
\hline Tumor differentiation grade: & & \\
\hline $\mathrm{G}_{1}$ high & $17(31.5)$ & $9(22.0)$ \\
\hline $\mathrm{G}_{2}$ moderate & $21(38.9)$ & $19(46.3)$ \\
\hline $\begin{array}{l}\mathrm{G}_{3} \text { low } \\
\text { Invasion depth into myome- } \\
\text { trium: }\end{array}$ & $16(29.6)$ & $13(31.7)$ \\
\hline$<1 / 2$ & $19(35.2)$ & $17(41.5)$ \\
\hline$>1 / 2$ & $35(64.8)$ & $24(58.5)$ \\
\hline
\end{tabular}

Morphologically the endometrial carcinomas with varied differentiation grade and the depth of invasion were demonstrated in surgical specimens from both groups of patients (see Table 2). In patients with aggregation of oncopathology in pedigrees, most of the tumors (46.3\%) were moderately differentiated with an invasion of less than half myometrium (41.5\%).

The analysis of the results of the immunohistochemical study of biomarkers in the EC revealed a significant variability of the individual parameters both by the number of tumor cells expressing tumor suppressors and by the proliferative activity (Fig. 1).

In particular, in patients of Group I, the number of tumor cells with the expression of $\mathrm{p} 53$ varied within the range of $5.3-83.0 \%$, p $21^{\mathrm{WAF} 1 / \mathrm{CIP}}-1.6-36.6 \%$, p16 ${ }^{\text {INK4a }}-3.0-37.4 \%$ and the marker of proliferation Ki-67 (2.0-89.7\%). In EC of patients from Group II, individual variations in the number of tumor cells with the expression of these proteins were slightly different: p53 (5.1-74.0\%), p21 WAF1/CIP $^{2.2-29.0 \%), ~ p 16 ~}{ }^{\text {INK4a }}$ (7.0-39.8\%), Ki-67 (9.3-64.2\%).

In EC of patients with aggregation of oncological pathology in families there was detected a larger number of cells with expression of protein suppressor p16 ${ }^{\text {INK4a }}(17.7 \pm 1.7 \% ; p=0.001)$ and lower numbers of cells with expression of p53 (30.9 $\pm 3.2 \% ; p=0.05)$ and the marker of $\mathrm{Ki}-67$ proliferating cells ( $26.9 \pm 2.7 \%$; $p=0.048$ ), compared to those in tumors of patients without aggregation of oncological pathology in families (12.0 $\pm 1.6 ; 37.7 \pm 2.8,36.7 \pm 3.4 \%$, respectively) (Fig. 2). Tumors of Groups I and II of EC patients were
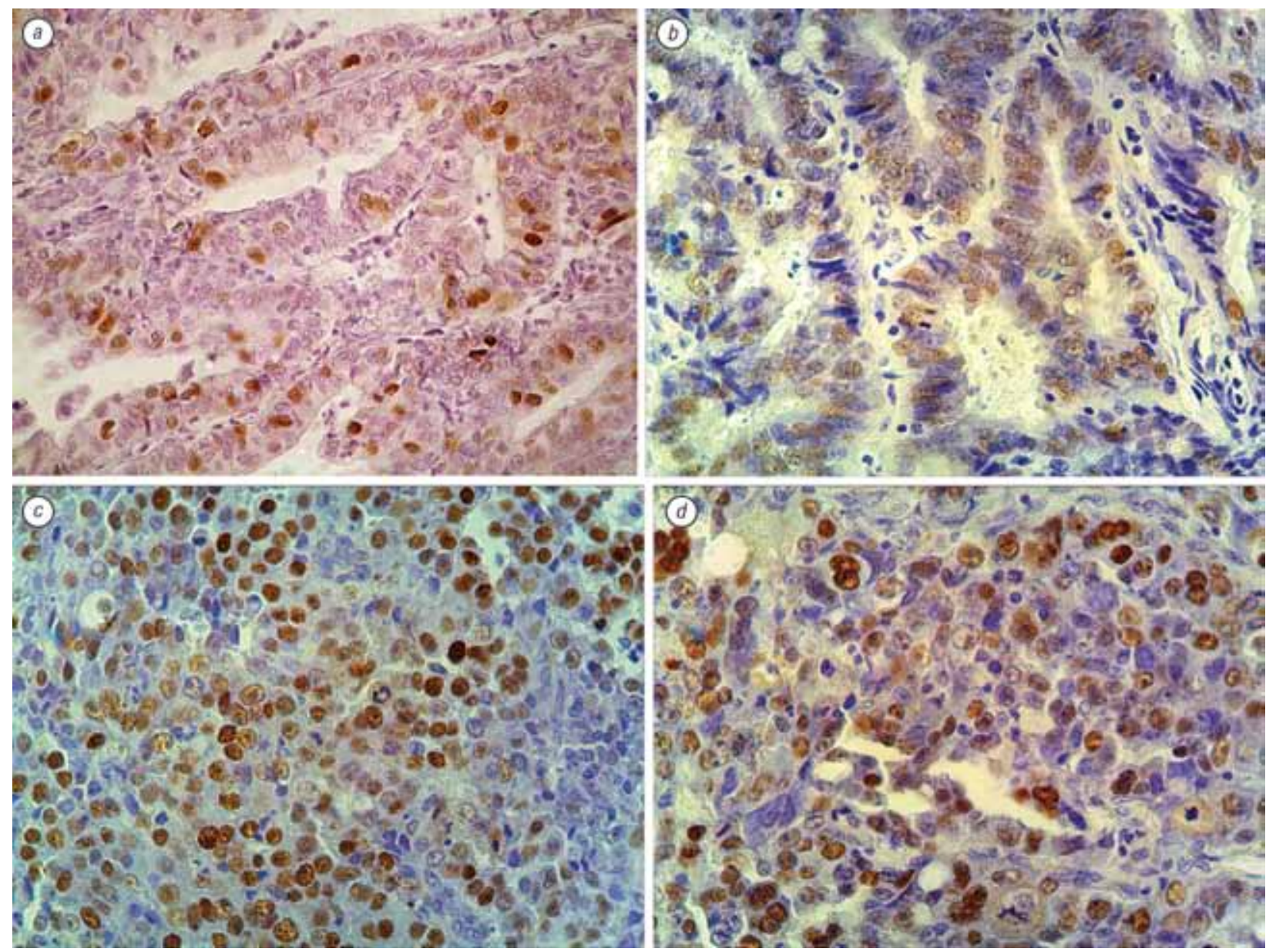

Fig. 1. Immunohistochemical expression of p21 ${ }^{\text {WAF } 1 / \mathrm{CIP}_{1}}(a), \mathrm{p} 16^{\mathrm{INK} 4 a}(b), \mathrm{p} 53(c), \mathrm{Ki}-67(d)$ in the endometrial adenocarcinoma. Counterstained by Mayer hematoxylin. $\times 400$ 
characterized by almost the same number of cells with expression of CDK inhibitor p21 $1^{\text {WAF } 1 / \mathrm{CIP}}$.

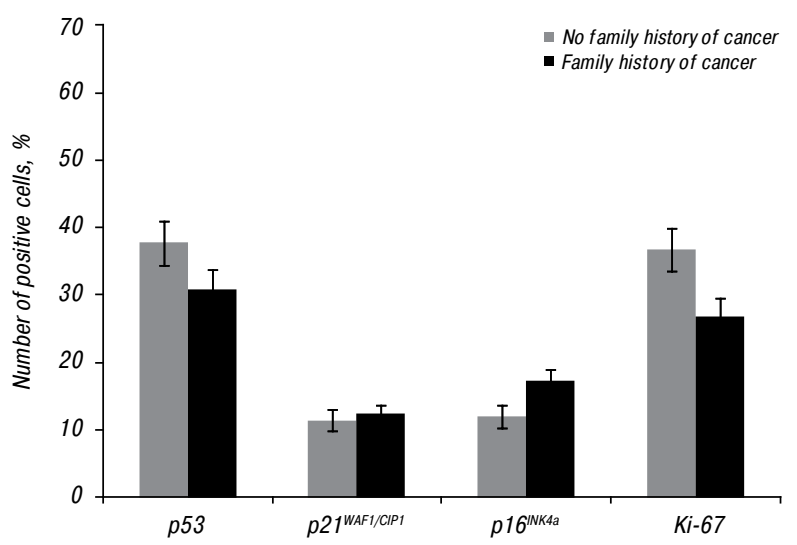

Fig. 2. Expression of biomarkers in tumors of EC patients depending on a family history of cancer

It was determined that in the group of patients with sporadic tumors prevailed high-proliferating (59.0\%) tumors, while in the patients with a family history of cancer, the number of such tumors was $43.9 \%(p<0.05)$. A correlation relationship was established $(r=0.6$; $p=0.01$ ) between the indexes of expression of the $\mathrm{Ki}-67$ and the p53. That is, the proliferation of sporadic EC cells significantly increased with high expression of p53. These data are confirmed by the results of cytofluorometric studies, which showed a significantly $(p<0.05)$ higher number of cells $(78.9 \pm 1.7 \%)$ in $\mathrm{G}_{0} /$ $G_{1}$ and lower in $S+G_{2}+M(21.1 \pm 0.5 \%)$ phases of the cell cycle in carcinomas of patients with an burdened family history of cancer compared to the patients with sporadic EC $(69.0 \pm 1.2$ and $31.0 \pm 0.7 \%$, respectively).

Thus, EC of patients with a family history of oncological pathology is characterized by a lower expression of the $\mathrm{Ki}-67$ proliferation marker and tumor suppressor protein p53 with the simultaneous growth of the expression of the CDK inhibitor p16 ${ }^{\mathrm{INK} 4 \mathrm{a}}$.

Analysis of the expression of biomarkers depending on differentiation grade of the EC showed that the number of tumor cells with the expression of proteins $\mathrm{Ki}-67$ and p53 in both groups of patients increased in the direction from high to moderate and low-differentiated tumors. However, the rates of $\mathrm{Ki}-67$ and p53 were significantly lower in $G_{1}$ and $G_{3}$ tumors of patients with family history of cancer (Table 3 ).

Table 3. Expression of biomarkers in EC of varying differentiation grade in patients without aggregation (Group I) and aggregation of tumor pathology in pedigrees (Group II)

\begin{tabular}{|c|c|c|c|c|}
\hline \multirow[t]{2}{*}{ Biomarker } & \multirow{2}{*}{$\begin{array}{l}\text { Groups } \\
\text { of patients }\end{array}$} & \multicolumn{3}{|c|}{ Cell number, $\%(M \pm m)$} \\
\hline & & $\overline{\mathrm{G}_{1}}$ & $\mathrm{G}_{2}$ & $\mathrm{G}_{3}$ \\
\hline$\overline{\mathrm{p} 53}$ & I & $33.2 \pm 5.0$ & $31.1 \pm 4.5$ & $53.9 \pm 5.5^{*, *+}$ \\
\hline & II & $18.5 \pm 5.4^{\#}$ & $27.1 \pm 3.8$ & $44.9 \pm$ \\
\hline p21 WAF $1 / \mathrm{CIP} 1^{-1}$ & I & $7.3 \pm 1.1$ & $16.7 \pm 4.3^{*, * \star}$ & $11.4 \pm 1.7$ \\
\hline & ॥ & $18.1 \pm 2.2^{\#}$ & $11.4 \pm 1.3$ & $9.2 \pm 3.0^{\star}$ \\
\hline p16 $6^{\text {INK4a }}$ & i & $17.2 \pm 2.8$ & $11.1 \pm 1.6$ & $7.2 \pm 0.9^{*}$ \\
\hline & II & $12.4 \pm 1.3$ & $16.5 \pm 1.4^{\#}$ & $20.3 \pm 3.2^{*}, \#$ \\
\hline Ki-67 & I & $24.9 \pm 2.4$ & $31.6 \pm 4.3$ & $52.9 \pm 4.6^{*, *+}$ \\
\hline & ॥ & $12.9 \pm 2.3^{\#}$ & $23.1 \pm 2.5$ & $42.1 \pm 3.3^{*, * *,}$ \\
\hline
\end{tabular}

Note: ${ }^{*} p<0.05$ compared with $\mathrm{G}_{1}$ tumors; ${ }^{* \star} p<0.05$ compared with $\mathrm{G}_{2}$ tumors; ${ }^{\star \star *} p<0.05$ compared with $\mathrm{G}_{1}$ tumors; ${ }^{*} p<0.05$ compared with Group II.

It should be noted that the change in the expression of the proteins $\mathrm{p} 16^{\text {INK4a }} \mathrm{Ta}$ p $21^{\text {WAF } 1 / \mathrm{CIP} 1}$ in EC, depending on differentiation grades in patients with burdened and non-burdened family history of cancer, was divergent. In tumors of patients with EC without aggregation of oncological pathology in pedigrees, along with the decrease of differentiation grade, there was observed a decrease in the number of cells with expression of protein p16 ${ }^{\text {INK4a }}$. At the same time, in the tumors of patients with a burdened family history of cancer, the number of cells expressing $p 16^{\text {INK4a }}$ protein was significantly $(p=0.03)$ higher in moderately and low-differentiated carcinomas compared with EC in Group I patients. The higher number of cells with expression of $\mathrm{p} 21^{\text {WAF } 1 / \mathrm{CIP}_{1} 1}$ was detected in $G_{2}(16.7 \pm 4.3)$ and $G_{3}$ tumors compared to $G_{1}$ tumors in patients with non-burdened family history of cancer $(p<0.05)$.

In carcinomas of patients with EC with a family history of cancer, a larger number of cells with expression of $\mathrm{p} 21^{\mathrm{WAF} 1 / \mathrm{CIP} 1}$ protein was observed in highly differentiated tumors, while with reduced differentiation grade the number of such cells significantly $(p<0.05)$ decreased, reaching the minimum values in low-differentiated neoplasms compared with those in tumors of patients without aggregation of oncopathology in family history.

It is known that one of the indicators of progression of malignant neoplasms is the depth of its invasion in adjacent tissues. Comparison of the expression of biomarkers in EC with the depth of invasion in myometrium showed that tumors with a deep $(>1 / 2)$ invasion of the patients from Groups I and II had a significantly higher number of cells with expression of the p53 protein and $\mathrm{Ki}-67$ proliferation marker compared to carcinomas without deep $(<1 / 2)$ invasion (Table 4$)$.

Table 4. Expression of biomarkers in EC depending on the depth of tumor invasion in myometrium and the burden of family history of cancer

\begin{tabular}{|c|c|c|c|c|}
\hline \multirow{5}{*}{ Biomarkers } & \multicolumn{4}{|c|}{ Family history of EC patients } \\
\hline & \multicolumn{2}{|c|}{$\begin{array}{c}\text { Without aggregation } \\
\text { of oncological pathology }\end{array}$} & \multicolumn{2}{|c|}{$\begin{array}{c}\text { With a family history } \\
\text { of cancer }\end{array}$} \\
\hline & \multicolumn{4}{|c|}{ The depth of invasion of the tumor in myometrium } \\
\hline & $<1 / 2$ & $>1 / 2$ & $<1 / 2$ & $>1 / 2$ \\
\hline & \multicolumn{4}{|c|}{ Expression of markers, $\%(\mathrm{M} \pm \mathrm{m})$} \\
\hline$\overline{p 53}$ & $36.8 \pm 3.1$ & $41.5 \pm 4.1$ & $22.8 \pm 3.0^{\#}$ & $36.9 \pm 3.5$ \\
\hline $\mathrm{p} 21^{\text {WAF } 1 / \mathrm{CIP} 1}$ & $9.4 \pm 1.7$ & $14.5 \pm 2.1$ & $14.3 \pm 1.7^{\#}$ & $10.4 \pm 0.2$ \\
\hline p16 $16^{\text {INK4a }}$ & $15.9 \pm 2.4$ & $9.6 \pm 1.4^{*}$ & $14.6 \pm 1.4$ & $18.8 \pm 0.5^{\star \star}, \#$ \\
\hline Ki-67 & $23.5 \pm 3.4$ & $48.1 \pm 3.7^{\star}$ & $18.9 \pm 2.4$ & $32.5 \pm 2.3^{\star \star}$ \\
\hline
\end{tabular}

Note: ${ }^{\star} p<0.05$ compared with tumors with invasion $<1 / 2$ myometrium in patients without aggregation of oncological pathology in family; ${ }^{\star \star} p<0.05 \mathrm{com}$ pared with in tumors with invasions $<1 / 2$ of myometrium in patients with a family history of cancer; ${ }^{*} p<0.05$ compared with tumors in patients without aggregation of oncological pathology in family.

Instead, in tumors that invaded less than $1 / 2$ of myometrium in patients with EC from Group I, expression levels of $\mathrm{p} 53$ and $\mathrm{Ki}-67$ were higher compared to those of patients from Group II. It should be noted that the change in expression of the proteins $\mathrm{p} 16^{\mathrm{INK} 4 \mathrm{a}}$ and $\mathrm{p} 21^{\text {WAF } 1 / \mathrm{CIP} 1}$ in EC with different depth of invasion of both groups was similar to the change in the expression of these proteins, depending on differentiation grade in these groups. Namely, in tumors with an invasion $>1 / 2$ into myometrium, in patients with a non-burdened family history of cancer, the higher number of cells with the expression of $\mathrm{p} 21^{\mathrm{WAF} 1 / \mathrm{CIP} 1}$ and lower number with $\mathrm{p} 16^{\mathrm{INK} 4 \mathrm{a}}$ expression were observed, compared with those in patients with a family history of cancer. 
In the study of life expectancy in patients with EC, depending on the burden of a family history of cancer, it was found that the overall 5-year survival rate in patients with EC from families without aggregation of oncological pathology was $78.0 \%$ and was significantly lower than in patients with a family history of cancer (92.0\%) (Fig. 3).

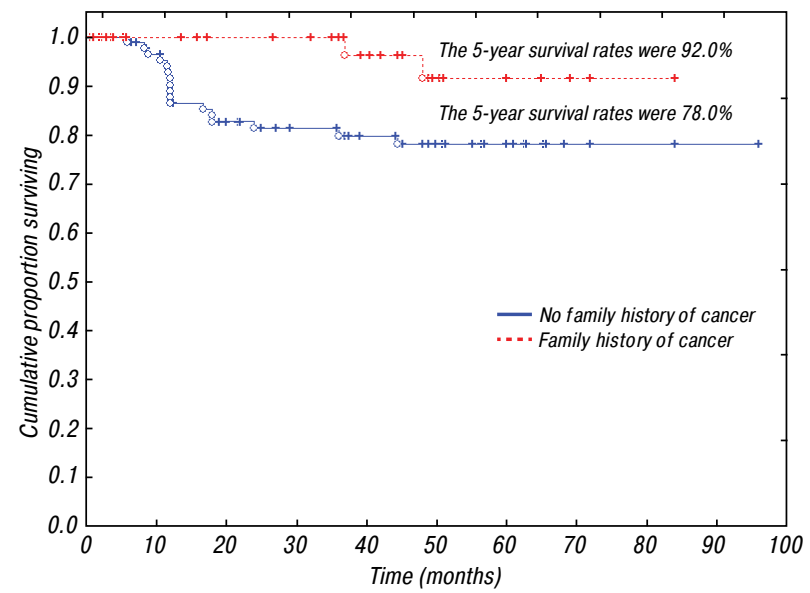

Fig. 3. Overall 5-year survival rate of EC patients depending on a family history of cancer (Kaplan - Meyer, Log-Rank Test, $p=0.04)$

So, the research has shown that in both groups of patients along with the progression of cancer, i.e. the decrease of differentiation grade and deep invasion of the tumor in myometrium, the expression of the $\mathrm{Ki}-67$ and the p53 progressively increased, but the expression of these markers was significantly more pronounced in sporadic ECs. Instead, the expression of CDK inhibitors $\mathrm{p} 16^{\mathrm{INK} 4 \mathrm{a}}$ and $\mathrm{p} 21^{\mathrm{WAF} 1 / \mathrm{CIP} 1}$ was differently directed, namely, in the tumors of EC patients with a family history of cancer, there was observed increased expression of $\mathrm{p} 16^{\mathrm{INK} 4 \mathrm{a}}$ and decreased expression of $\mathrm{p} 21^{\mathrm{WAF} / \mathrm{CIP} 1}$ in low-differentiated and deeply invasive tumors compared to moderately and highly differentiated tumors with invasion $\leqslant 1 / 2$ in myometrium. The phenotypic features of tumors of patients without aggregation of oncological pathology in pedigrees and from families with a family history of cancer are associated with the overall 5-year survival rate of these patients.

\section{DISCUSSION}

Numerous studies have shown that EC course is characterized by significant variability, which is determined by the spectrum of genetic disorders, in particular, suppressor genes whose protein products are involved in various signaling pathways for cell proliferation control, in particular p53, p2 $1^{\mathrm{WAF} / \mathrm{CIP} 1}$ and p16 ${ }^{\text {INK4a }}[24,25]$.

One of the risk factors for the development of the tumor process, including EC, is a burdened family history of cancer since it is genetic changes that determine the biology of the tumor modulating the prognosis of the disease course [4].

In our study, the differences in the clinical course of the disease in patients without aggregation of oncological pathology in pedigrees and family history of cancer have been established. In particular, significantly higher overall 5-year survival $(92.0 \%)$ was observed in patients with $\mathrm{EC}$ with a family history of cancer, compared with this in patients without aggregation of oncological pathology in the pedigree (78.0\%). A similar view is expressed by other researchers, who noticed a more favorable course of the disease in patients with hereditary EC, compared to patients with sporadic EC [23].

Detected differences in the life expectancy of patients from Groups I and II were associated with certain molecular-biological characteristics of their tumors. Thus, in tumors of patients with a burdened family history of cancer, there was a significantly lower expression of the p53 protein and the marker of proliferating cells Ki-67 and a higher level of $p 16^{\text {INK4a }}$ than in EC of patients without aggregation of oncological pathology in families. Along with this, tumors of the studied groups of patients revealed discrepancies in the expression of CDK inhibitors $\mathrm{p} 21^{\mathrm{WAF} 1 / \mathrm{CIP} 1}$ and $\mathrm{p} 16^{\mathrm{INK} 4 \mathrm{a}}$. In patients with a burden family history of cancer, there was found a higher number of cells with the expression of $\mathrm{p} 16^{\mathrm{INK} 4 \mathrm{a}}$ and lower of $\mathrm{p} 21^{\mathrm{WAF} 1 / \mathrm{CIP} 1}$ in lowdifferentiated carcinomas and deep invasion of myometrium compared with tumors with high differentiation grade and with invasion $<1 / 2$. Detected phenotypic features of tumors of patients with a burdened cancer history may be due to a specific spectrum of genetic disorders that occur in various signaling pathways controlling endometrial cell proliferation, including cell cycle $\mathrm{p} 53$, $\mathrm{p} 21^{\mathrm{WAF} 1 / \mathrm{CIP} 1}$, and $\mathrm{p} 16^{\text {INK4a }}$.

Possibly, the lower proliferative activity in EC of patients with a burdened family history of cancer is due to the effect of suppressor protein $\mathrm{p} 16^{\mathrm{INK} 4 \mathrm{a}}$, which inhibits the CDK4/6 binding to cyclin D1, resulting in $\mathrm{pRb}$ remaining in a hypophosphorylated state in a complex with E2F and thus blocking $G_{1} / S$ checkpoint. The latter leads to the accumulation of cells in the $G_{0} / G_{1}$ phase of the cell cycle, which we have established during a cytometric examination of the distribution of endometrial tumor cells by the phases of the mitotic cycle. The results of the study showed a significant $(p<0.05)$ increase in the number of tumor cells in the $G_{0} / G_{1}$ phase, in patients with a family history of cancer compared with sporadic EC.

Taking into account the function of the p16 protein in the cell cycle, it is possible that its increase in $G_{3}$ tumors may be the result of a feedback mechanism in response to the increased proliferative activity of tumor cells [26].

According to the literature, in the majority of malignant tumors of different genesis, there are genetic disorders of the gene TP53 [27]. In EC, the aberrant expression of p53 is determined by the absence of expression of its protein product, or its overexpression (over $50.0 \%$ of tumor cells with p53 expression). In this case, EC with aberrant expression of p53 are characterized by a high degree of malignancy, and the patients with such tumors showed an unfavorable course of the disease [28-30]. In our study, it was found that 
in patients with a burdened family history of cancer, the number of tumors with the expression of p53 $>50.0 \%$ was significantly lower $\left(X^{2}=3.99 ; p=0.04\right)$, compared to the tumors of the patients without aggregation of tumor pathology in pedigree (37.0\%).

A small number of tumor cells with $\mathrm{p} 21^{\mathrm{WAF} 1 / \mathrm{CIP} 1}$ protein expression in low-differentiated tumors of EC patients with a family history of cancer may result from the aberrant functioning of the p53 protein that is unable to activate $\mathrm{p} 21^{\mathrm{WAF} 1 / \mathrm{CIP} 1}$, or activation of $\mathrm{p} 21^{\mathrm{WAF} 1 / \mathrm{CIP} 1}$ is provided by the $\mathrm{p} 53$-independent mechanism.

In contrary, in sporadic tumors, the decrease in the expression of $\mathrm{p} 16^{\mathrm{INK} 4 \mathrm{a}}$ leads to the activation of a complex of CDK4/6 and cyclin D1, resulting in the phosphorylation of $\mathrm{Rb}$ and the release of E2F, which activates the transcription of genes that activate the cellular cycle of $\mathrm{S}$ phase, and the $\mathrm{Ki}-67$ increase [31]. The reason for the decrease in the expression of $\mathrm{p} 16^{\text {INK4a }}$ in EC cells of patients without aggregation of tumor pathology in families may be both the methylation of the promoter of the CDKN2A/p16 INK4A gene and the homozygous deletion of 1 exon of this gene [32]. It has been shown that the expression of the p16 $16^{\text {INK4a }}$ protein is inversely correlated with differentiation grade of tumor cells in most endometrioid carcinomas [33], and in sporadic EC p16 INK4A inactivation is more often observed, especially in cases with a more aggressive course of the disease $[23,34]$. These data are in agreement with the results of our study, which found that tumors in patients with EC without a burdened family history of cancer differed by a smaller number of cells with expression of $\mathrm{p} 16^{\mathrm{INK} 4 \mathrm{a}}$ protein in direct correlation with survival rates compared to patients with a family history of cancer.

It could not be excluded that high proliferative activity in Group I of patients is associated with disturbances in the signal pathway $\mathrm{p} 53 \rightarrow \mathrm{p} 21^{\mathrm{WAF} 1 / \mathrm{CIP} 1}+\mathrm{CDK} 4,6$ and cyclin D, CDK2 and cyclin A, E. The parallel increase in the number of p53 and Ki-67-positive tumor cells revealed by us (as confirmed by correlation analysis) indicates accumulation of mainly functionally aberrant p53 protein in tumors of patients without an aggregated family history of oncological pathology.

The identified alterations in cell proliferation in the investigated EC may be associated not only with the TP53 gene disturbance but also with the inactivation of one of the regulators of its expression, the MDM2 protein [35, 36]. According to our previous studies, with a decrease in EC differentiation grade, an increase in the expression ratio of p53/MDM2 is observed, which is due to a drastic decrease in the content of the MDM2 protein. Along with this, the number of tumors with no MDM2 expression increases [37].

According to the literature, a number of solid tumors possess a high expression of $\mathrm{p} 21^{\mathrm{WAF} / \mathrm{CIP} 1}$, while retaining the ability to exhibit high proliferative activity. According to the authors, such tumors may have specific phosphorylated forms of p21 WAF $1 / \mathrm{CIP} 1^{\text {(T57, }}$ $\mathrm{T} 145, \mathrm{~S} 146$ or $\mathrm{S} 130$ ) that have lost their inhibitory functions [38-40]. That is, the simultaneous growth of the expression of $\mathrm{p} 21^{\mathrm{WAF} 1 / \mathrm{CIP} 1}$ and $\mathrm{Ki}-67$ proteins in low-differentiated EC of patients without aggregation of oncological pathology in pedigrees compared with their expression in high and moderately differentiated tumors may indicate a lack of inhibitory effect of $\mathrm{p} 21^{\mathrm{WAF} 1 / \mathrm{CIP} 1}$ protein on proliferation in tumor cells.

Summing up the results of our study we can conclude that a more favorable prognosis of patients with EC with aggregation of tumor pathology in pedigrees is associated with certain phenotypic peculiarities of their tumors, which predetermine a lower degree of malignancy of these tumors, compared with patients with sporadic EC.

Another mechanism that can explain the more favorable prognosis of the disease is the presence of microsatellite instability in the tumors of such patients, which correlates with a large number of immunocompetent cells in the tumor microenvironment, in particular, intratumoral lymphocytes, which enhance the immune response [41].

Therefore, the biological heterogeneity of the $\mathrm{EC}$ associated with the hereditary factors is determined, which modulates molecular-biological features of the tumor, and influences the EC aggressiveness and the course of the disease.

\section{REFERENCES}

1. Fedorenko ZP, Michailovich YYo, Goulak LO, et al. Cancer in Ukraine, 2015-2016. Incidence, mortality, activities of oncological service. Bull Natl Cancer Registry of Ukraine 2017; (18). 86 p.

2. Colombo N, Creutzberg C, Amant F, et al; ESMOESGO-ESTRO Endometrial Consensus Conference Working Group. ESMO-ESGO-ESTRO Consensus Conference on Endometrial Cancer: diagnosis, treatment and follow-up. Ann Oncol 2016; 27: 16-41.

3. Glushchenko NM, Nesina IP, Iurchenko NP, et al. Risk assessment of cancer of the female reproductive system. Exp Oncol 2014; 36: 207-11.

4. Wong A, Ngeow J. Hereditary syndromes manifesting as endometrial carcinoma: how can pathological features aid risk assessment? Biomed Res Int 2015; 2015: 219012.

5. Imyanitov EN. Screening for persons with hereditary predisposition to cancer. Pract Oncol 2010; 11: 102-9 (in Russian).

6. Win AK, Lindor NM, Winship I, et al. Risks of colorectal and other cancers after endometrial cancer for women with Lynch syndrome. J Natl Cancer Inst 2013; 105: 274-9.

7. Lyubchenko LN, Bateneva YI, Vorotnikov IK, et al. Hereditary breast cancer: genetic and clinical heterogeneity, molecular diagnostics, surgical prophylaxis in at-risk groups. Adv Mol Oncol 2014; 1: 16-25 (in Russian).

8. Lancaster JM, Powell CB, Chen LM, Richardson DL; SGO Clinical Practice Committee. Society of Gynecologic Oncology statement on risk assessment for inherited gynecologic cancer predispositions. Gynecol Oncol 2015; 136: 3-7.

9. Tashiro H, Katabuchi H. The relationship between estrogen and genes in the molecular pathogenesis of endometrial cancer. Curr Obstet Gynecol Rep 2014; 3: 9-17.

10. Nishimukai A, Yagi T, Yanai A, et al. High Ki-67 expression and low progesterone receptor expression could independently lead to a worse prognosis for postmenopausal patients with estrogen receptor-positive and HER2-negative breast cancer. Clin Breast Cancer 2015; 15: 204-11. 
11. Hanahan D, Weinberg RA. Hallmarks of cancer: the next generation. Cell 2011; 144: 646-74.

12. Milde-Langosch K, Riethdorf S. Role of cell-cycle regulatory proteins in gynecological cancer. J Cell Physiol 2003; 196: 224-44.

13. Orlando S, Gallastegui E, Besson A, et al. p27Kip1 and p21Cip1 collaborate in the regulation of transcription by recruiting cyclin-Cdk complexes on the promoters of target genes. Nucleic Acids Res 2015; 43: 6860-73.

14. Kitagishi $Y$, Matsuda S, Minami A, et al. Regulation in cell cycle via p53 and PTEN tumor suppressors. Cancer Stud Mol Med Open J 2014; 1: 1-7.

15. Lee EY, Muller WJ. Oncogenes and tumor suppressor genes. Cold Spring Harb Perspect Biol 2010; 2: a003236.

16. Koh VM, Shi YX, Tang QH. P16 and retinoblastoma protein expression in endometrial carcinoma and clinical significance. Eur J Gynaecol Oncol 2011; 32: 309-15.

17. Skirnisdottir I, Seidal T. Association of p21, p21 p27 and p21 p53 status to histological subtypes and prognosis in lowstage epithelial ovarian cancer. Cancer Genomics Proteomics 2013; 10: 27-34.

18. Kawamura T, Suzuki J, Wang YV, et al. Linking the p53 tumour suppressor pathway to somatic cell reprogramming. Nature 2009; 460: 1140-4.

19. Buchynska LG, Nesina IP. Expression of the cell cycle regulators p53, p21(WAF1/CIP1) and p16(INK4a) in human endometrial adenocarcinoma. Exp Oncol 2006; 28: 152-5.

20. Committee on Practice Bulletins-Gynecology; Society of Gynecologic Oncology. ACOG Practice Bulletin No. 147: Lynch syndrome. Obstet Gynecol 2014; 124: 1042-54.

21. Kurman RJ, Carcangiu ML, Herrington CS, Young RH. WHO classification of tumours of female reproductive organs, 4th Ed. Lyon: IARC, 2014. 307 p.

22. Lynch PM. Cancer risks after endometrial cancer in mismatch repair mutation carries. J Natl Cancer Inst 2013; 105: 251-2.

23. Lynch HT, Lynch JF, Attard TA. Diagnosis and management of hereditary colorectal cancer syndromes: Lynch syndrome as a model. CMAJ 2009; 181: 273-80.

24. Felix AS, Sherman ME, Hewitt SM, et al. Cell-cycle protein expression in a population-based study of ovarian and endometrial cancers. Front Oncol 2015; 5: 25.

25. Le Page C, Huntsman DG, Provencher DM, MesMasson AM. Predictive and prognostic protein biomarkers in epithelial ovarian cancer: recommendation for future studies. Cancers (Basel) 2010; 2: 913-54.

26. Saegusa M, Machida BD, Okayasu I. Possible associations among expression of p14(ARF), p16(INK4a), p21(WAF1/CIP1), p27(KIP1), and p53 accumulation and the balance of apoptosis and cell proliferation in ovarian carcinomas. Cancer 2001; 92: 1177-89.

27. Kastenhuber ER, Lowe SW. Putting p53 in context. Cell 2017; 170: 1062-78.

28. Wei JJ, Paintal A, Keh P. Histologic and immunohistochemical analyses of endometrial carcinomas: experiences from endometrial biopsies in 358 consultation cases. Arch Pathol Lab Med 2013; 137: 1574-83.

29. Han G, Sidhu D, Duggan MA, et al. Reproducibility of histological cell type in high-grade endometrial carcinoma. Mod Pathol 2013; 26: 1594-604.

30. Talhouk A, McConechy MK, Leung S, et al. A clinically applicable molecular-based classification for endometrial cancers. Br J Cancer 2015; 113: 299-310.

31. Mints M, Mushtaq M, Iurchenko N, et al. Mitochondrial ribosomal protein S18-2 is highly expressed in endometrial cancers along with free E2F1. Oncotarget 2016; 7: 22150-8.

32. Hu ZY, Tang LD, Zhou Q, et al. Aberrant promoter hypermethylation of p16 gene in endometrial carcinoma. Tumour Biol 2015; 36: 1487-91.

33. Koh VM, Shi YX, Tang QH. P16 and retinoblastoma protein expression in endometrial carcinoma and clinical significance. Eur J Gynaecol Oncol 2011; 32: 309-15.

34. Semczuk A, Boltze C, Marzec B, et al. p16 ${ }^{\mathrm{INK} 4 \mathrm{~A}}$ alterations are accompanied by aberrant protein immunostaining in endometrial carcinomas. J Cancer Res Clin Oncol 2003; 129: 589-96.

35. O'Hara AJ, Bell DW. The genomics and genetics of endometrial cancer. Adv Genomics Genet 2012; 2012: 33-47.

36. Xu H, Zhang Z, Li M, Zhang R. MDM2 promotes proteasomal degradation of $\mathrm{p} 21^{\text {Wafl }}$ via a conformation change. J Biol Chem 2010; 285: 18407-14.

37. Buchynska LG, Nesina IP, Kashuba EV. Different trends of p53, MDM2 and p14 ARF expression patterns in endometrial adenocarcinomas versus hyperplasia. Exp Oncol 2007; 29: 287-94.

38. Stivala LA, Cazzalini O, Prosperi E. The cyclindependent kinase inhibitor $\mathrm{p} 21^{\mathrm{CDKN} 1 \mathrm{~A}}$ as a target of anti-cancer drugs. Curr Cancer Drug Targets 2012; 12: 85-96.

39. McKenzie PP, Danks MK, Kriwacki RW, Harris LC. P $21^{\text {Waf } 1 / \text { Cip } 1}$ dysfunction in neuroblastoma: A novel mechanism of attenuating $\mathrm{G}_{0}-\mathrm{G}_{1}$ cell cycle arrest. Cancer Res 2003; 63: 3840-4.

40. Child ES, Mann DJ. The intricacies of $\mathrm{p} 21$ phosphorylation: Protein/protein interactions, subcellular localization and stability. Cell Cycle 2006; 5: 1313-9.

41. Lynch HT, Drescher KM, de la Chapelle A. Immunology and the Lynch syndrome. Gastroenterology 2008; 134: 1246-9. 